\title{
Study on the Hepatoprotective Effect of Oyster Mushroom (Pleurotus Florida) Against Paracetamol Induced Liver Damage in Wistar Albino Rats
}

\author{
Afroza Khanam Sumy ${ }^{1}$, Nasim Jahan ${ }^{2}$, Nayma Sultana ${ }^{3}$
}

\begin{abstract}
Background: Liver damage can be occurred due to prolonged use of higher doses of some drugs, exposure to some chemicals or infectious agents. But liver protective drugs are not available in modern medicine. Some hepatoprotective herbal medicines are often used in the treatment of liver damage. Objective: This experimental study was carried out to observe the hepatoprotective effect of Oyster mushroom (Pleurotus florida) against paracetamol induced liver damage in Wistar albino rats. Method: This experimental study was carried out in the Department of Physiology, Sir Salimullah Medical College (SSMC), Dhaka from $1^{\text {st }}$ July 2009 to $30^{\text {th }}$ June 2010. A total number of 34 Wistar albino rats, age ranged from 90 to 120 days, weighing between 150 to 210 grams were selected for the study. After acclimatization for 14 days, they were divided into two groups, control group (Group A) and experimental group (Group B- mushroom pretreated and paracetamol treated group). Control group again subdivided into group $\mathrm{A}_{1}$ (baseline control) and group $\mathrm{A}_{2}$ (paracetamol treated control group). All groups of animals received basal diet for 30 consecutive days. Group $A_{1}$ consisted of 10 rats, received propylene glycol ( $2 \mathrm{ml} / \mathrm{kg}$ bw, orally) only on $30^{\text {th }}$ day. Group $\mathrm{A}_{2}$ consisted of 14 rats, received single dose of paracetamol suspension ( $750 \mathrm{mg} / \mathrm{kg}$ bw, orally) only on $30^{\text {th }}$ day. Group B consisted of 10 rats, received mushroom extract ( $200 \mathrm{mg} / \mathrm{kg}$ bw, orally) for 30 consecutive days and paracetamol suspension $\left(750 \mathrm{mg} / \mathrm{kg}\right.$ bw, orally) only on $30^{\text {th }}$ day. All the animals were sacrificed on $31^{\text {st }}$ day. Then blood and liver samples were collected. Initial body weight, final body weight and liver weight were measured. Then measurement of aspartate aminotransferase (AST) and alanine aminotransferase (ALT) in serum and assessment of malondialdehyde (MDA) concentration in liver tissue homogenate were done by using standard laboratory kits. The statistical analysis was done by one way ANOVA and Bonferroni test as applicable. Result: The mean serum AST, ALT levels and in the liver tissue MDA concentration were significantly $(\mathrm{p}<0.001)$ higher in paracetamol treated group in comparison to those of baseline control group. Again, the mean serum AST $(\mathrm{p}<0.05)$, ALT $(\mathrm{p}<0.05)$ levels and in the liver tissue homogenate MDA concentration $(\mathrm{p}<0.001)$ were significantly lower in mushroom pretreated and paracetamol treated group (experimental group) when compared to those of only paracetamol treated group (control). Conclusion: This study reveals that Oyster mushroom (Pleurotus florida) which is excellently edible and nutritious, may have some hepatoprotective role.
\end{abstract}

Key words: hepatoprotective, oyster mushroom, malondialdehyde, tissue homogenate

J Bangladesh Soc Physiol. 2010 December; 5(2): 46-52 For author affiliations, see end of text.

http://www.banglajol.info/index.php/JBSP

\section{Introduction}

$\mathbf{T}$ he liver is an important metabolic organ. Besides metabolic functions it performs bile formation and secretion, synthesis of some proteins including clotting factors, detoxification of drugs and endogenous compounds, storage of vitamins and minerals ${ }^{1}$. 
Liver is continuously exposed to a variety of toxic agents like drugs, chemicals, microbiological and viral agents, that may interfere the hepatic functions and may cause hepatitis. If the hepatitis remain untreated, it will develop chronicity and may progress to subacute hepatic failure, hepatic encephalopathy, hepatic fibrosis leading to cirrhosis and hepatocellular carcinoma etc ${ }^{2}$.

Paracetamol is an antipyretic and analgesic drug which is widely used and is readily available without prescription in our country. When it is taken at toxic dose, it can cause centrilobular necrosis, liver function failure and death in experimental animals as well as in human ${ }^{3}$. Paracetamol is widely used drug to induce hepatic damage in experimental model. The mechanism of paracetamol toxicity is over production of reactive oxygen species (ROS) such as superoxide radicals, hydrogen radicals and hydroxyl radicals. Excess levels of ROS can attack biological molecules such as DNA, protein, phospholipids, which leads to lipid peroxidation and depletion of antioxidant enzymes such as superoxide dismutase (SOD), catalase (CAT) and glutathione peroxidase $\left(\mathrm{GP}_{\mathrm{x}}\right)^{5}$. Serum transaminases have long been considered as sensitive indicator of hepatic damage.

The Pleurotus mushroom comprises about 40 species that reffered to as "Oyster mushroom", which is excellently edible and nutritious ${ }^{6}$. Oyster mushroom can suppress toxin induced increased levels of serum aminotransferase enzymes in animals when compared to those of mushroom untreated rats, indicating the hepatoprotective effect of mushroom ${ }^{7,8}$. Again, some researchers observed the significant lipid peroxidation inhibition activity of Oyster mushroom in rats ${ }^{9}$.

Now a days, there is increasing need for agents to protect the liver from damage. But in modern medicine reliable liver protective drugs are not available. Ayurveda recommended some medicinal preparations for the treatment of liver disorder.However, little is known about the hepatoprotective effect of mushroom. Oyster mushroom which has high nutritive and medicinal value is cultivated and harvested in Bangladesh all over the year. It is reasonably cheap, easily available and relatively safe in comparison to other mushrooms. Therefore, the present study was designed to observe the hepatoprotective effect of oyster mushroom (Pleurotus florida) in experimental animals after inducing hepatotoxicity by paracetamol by measuring aminotransferase enzymes levels in serum and malondialdehyde (MDA) concentration in liver tissue.Moreover, the finding of this study may be helpful to make this mushroom acceptable among the people as a good food for the prevention of liver diseases.

\section{Methods}

This experimental study was conducted from July 2009 to June 2010 in the Department of Physiology, SSMC, Mitford, Dhaka. A total number of thirty four (34) apparently healthy Wistar albino male rats, weighing between 150 to 210 gram, age ranged from 90 to 120 days were used in the present study .The animals were purchased from the animal house of Bangladesh Council of Scientific and Industrial Research (BCSIR), Dhaka. Ethical permission was taken from the ethical committee of SSMC, Dhaka. Prior to conducting the study the animals were acclimatized for 14 days under 12 hour dark and light schedule. During this period they had free access to food and water ad libitum. Then, they were divided into two groups, control group (Group A) and experimental group (Group Bmushroom pretreated and paracetamol treated group). Control group again subdivided into group $A_{1}$ (baseline control) and group $A_{2}$ (paracetamol treated control group). All groups of animals received basal diet for 30 consecutive days. Group $A_{1}$ consisted of 10 rats, received propylene glycol ( $2 \mathrm{ml} / \mathrm{kg}$ bw, orally) only on $30^{\text {th }}$ day. Group $\mathrm{A}_{2}$ consisted of 14 rats, received single dose of paracetamol suspension ( $750 \mathrm{mg} / \mathrm{kg}$ bw, orally) only on $30^{\text {th }}$ day. Group B consisted of 10 rats, received mushroom extract (200 mg/ kg bw, 
orally) for 30 consecutive days and paracetamol suspension (750 mg/ kg bw, orally) only on $30^{\text {th }}$ day.During the study period, one rat of paracetamol treated control group died which may be due to toxic effect of paracetamol. After giving paracetamol and mushroom all the animals including the baseline control rats, were sacrificed on $31^{\text {st }}$ day. After 14 days of acclimatization, body weight was measured (initial bw). Again, final body weight (final bw) of rats before sacrifice on $31^{\text {st }}$ day were taken. Then blood and liver samples were collected. Liver was washed in ice cold saline. Then it was wiped in tissue paper and the weight was measured. Determination of serum aspartate aminotransferase (AST) and alanine aminotransferase (ALT) enzymes levels were done by enzymatic method in the laboratory of Department of Physiology, SSMC. Assessment of malondialdehyde content in liver tissue homogenate was done by using standard laboratory kits in the laboratory of Department of Biochemistry and Molecular Biology, Jahangirnagar University. Statistical analysis was done by ANOVA and Bonferroni test by using SPSS, version 15.

\section{Result}

Initial body weight of group $A_{1}, A_{2}$ and $B$ were almost similar and showed no statistically significant difference of this values between group $A_{1}$ vs $A_{2}, A_{1}$ vs $B$ and $A_{2}$ vs $B$ (Figure1).Again, no statistical significant difference of final body weight was observed among the groups (Figure1).

Percent (\%) of change in body weight was significantly $(\mathrm{p}<0.05)$ lower in group $B$ when compared to that of group $A_{1}$. Whereas, the percent (\%) of change in body weight were non significant between group $A_{1}$ vs $A_{2}$ and $A_{2}$ vs $B$ (Figure 2).

The liver weight was higher in group $A_{2}$ when compared to that of group $A_{1}$ and $B$, though it was statistically significant $(p<0.01)$ between group $A_{1}$ vs $A_{2}$, but non significant between group $A_{2}$ vs $B$. Again, liver weight of group $B$

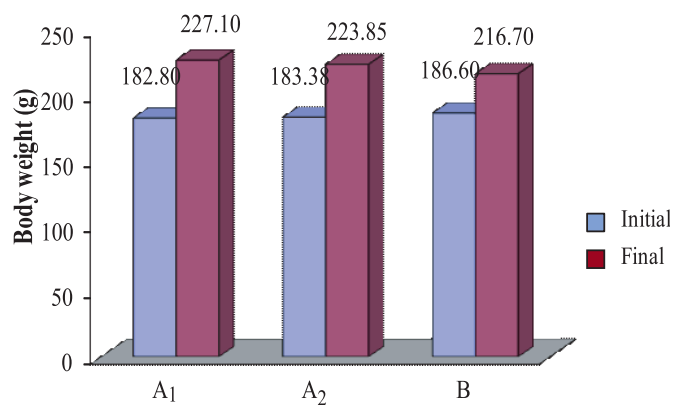

Control group

Group A1 (baseline control group)

Group A2 (paracetamol treated control group)

Experimental group

Group B (mushroom pretreated and paracetamol treated group)

Figure 1: Initial and final body weight of rats $(\mathrm{n}=33)$

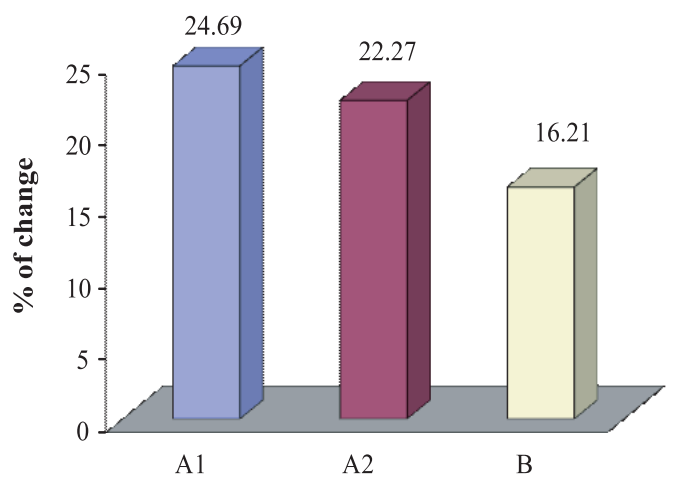

Control group

Group A1 (baseline control group)

Group A2 (paracetamol treated control group)

Experimental group

Group B (mushroom pretreated and paracetamol treated group)

Figure 2: Mean percent of change from final weight (F) to initial weight (I) in different groups $(\mathrm{n}=33)$

was higher than that of group $A_{1}$, but the difference was non significant (Figure 3 ).

Mean serum level of AST and ALT were significantly higher in group $A_{2}(p<0.001)$ and group $B(p<0.05$ and $p<0.001$, respectively) in comparison to that of group $A_{1}$. Again, this level of group $B$ was significantly $(p<0.05)$ lower than that of group $A_{2}$ (Table I). 


\section{Article}

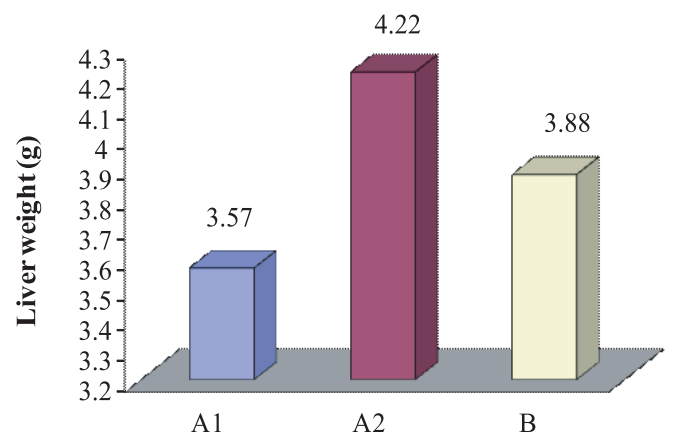

Control group

Group A1 (baseline control group)

Group A2 (paracetamol treated control group)

Experimental group

Group B (mushroom pretreated and paracetamol treated group)

Figure 3: Mean liver weight of rat in different groups $(\mathrm{n}=33)$

Table I: Serum Aminotransferase enzymes level in different groups $(\mathrm{n}=33)$

\begin{tabular}{lccc}
\hline Group & $\mathrm{n}$ & $\begin{array}{c}\text { Serum } \\
\text { AST(U/L) }\end{array}$ & $\begin{array}{c}\text { Serum } \\
\text { ALT(U/L) }\end{array}$ \\
\hline Group $\mathrm{A}_{1}$ & 10 & $66.10 \pm 8.58$ & $56.70 \pm 7.48$ \\
Group $\mathrm{A}_{2}$ & 13 & $106.47 \pm 20.41$ & $97.08 \pm 19.21$ \\
Group B & 10 & $87.40 \pm 17.48$ & $81.80 \pm 9.77$ \\
\hline
\end{tabular}

Statistical analysis

\begin{tabular}{lcc}
\hline & \multicolumn{2}{c}{$\mathrm{p}$ value } \\
\hline $\mathrm{A}_{1}$ vs $\mathrm{A}_{2}$ & $0.000^{* * *}$ & $0.000^{* * *}$ \\
$\mathrm{~A}_{1}$ vs B & $0.024^{*}$ & $0.000^{* * *}$ \\
$\mathrm{~A}_{2}$ vs B & $0.033^{*}$ & $0.042^{*}$ \\
\hline
\end{tabular}

Results are expressed as Mean \pm SD. Statistical analysis was done by ANOVA test and then perform Bonferroni test to compare between two groups. Figures in parentheses indicate ranges.

Control group

Group $A_{1}$ (baseline control group)

Group $A_{2}$ (paracetamol treated group)

Experimental group

Group B (mushroom pretreated and paracetamol treated group)

$\mathrm{n}=$ Total number of subjects.

$*=$ Significant at $\mathrm{p}<0.05$. $* * *=$ Significant at $\mathrm{p}<0.001$.
Hepatoprotective Effect of Oyster Mushroom

Again, MDA concentration in liver tissue homogenate was significantly $(\mathrm{p}<0.001)$ higher in group $A_{2}$ in comparison to that of group $A_{1}$. On the other hand, MDA concentration was almost similar and showed no statistically significant difference between group $\mathrm{A}_{1}$ and $\mathrm{B}$. Again, this value was significantly $(\mathrm{p}<0.001)$ lower in group $\mathrm{B}$ when compared to that of group $A_{2}$ (Figure 4).

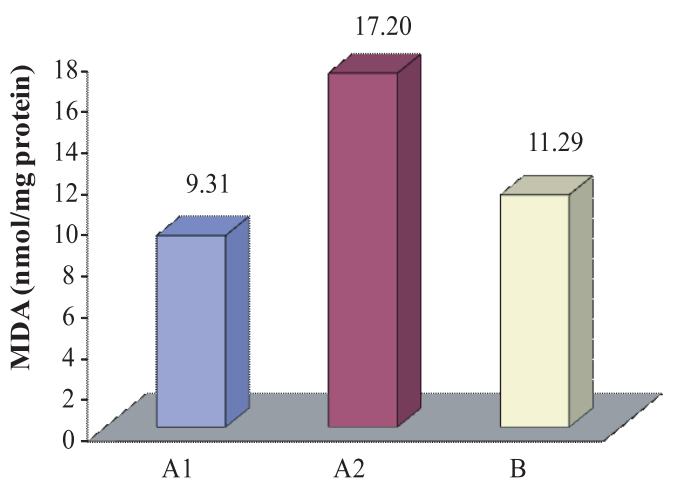

Control group

Group A1 (baseline control group)

Group A2 (paracetamol treated control group)

Experimental group

Group B (mushroom pretreated and paracetamol treated group)

Figure 4: Malondialdehyde (MDA) concentration in liver in different groups $(\mathrm{n}=33)$

\section{Discussion}

In this study, the final body weight of all the animals was increased than their initial weight, but this was statistically non-significant. This finding is in agreement with that of some other researchers ${ }^{17}$.Again, the percent (\%) change of body weight from final body weight to initial body weight was significantly $(\mathrm{p}<0.05)$ lower in mushroom pretreated and paracetamol treated group when compared to that of baseline control group is similar to the finding made by other investigators ${ }^{19}$.Moreover, the liver weight was significantly $(\mathrm{p}<0.001)$ higher in paracetamol treated rats when compared to that of baseline control group, but non-significantly higher when compared to that of mushroom pretreated and 
paracetamol treated group. Again, nonsignificant difference in this value was observed in mushroom pretreated and paracetamol treated rats in comparison to that of baseline control rats. However, no published data are available to compare these findings.

In this study, serum aspartate aminotransferase (AST) and alanine aminotransferase (ALT) enzyme levels in serum and malondialdehyde (MDA) concentration in liver tissue homogenate were significantly higher in paracetamol treated rats in comparison to those of baseline control rats is also similar to the findings observed by different research workers 10,11. Again, significantly lower level of these values were observed in mushroom pretreated and paracetamol treated group when compared to those of paracetamol treated rats are in agreement with the observations of some other research workers $7,8,9,10$.

Extensive studies on the development of hepatic damage in animals by toxin had shown that hepatocellular injury alters cell membrane permeability leading to leakage of enzymes from the cells. This leakage causes a decrease in the levels of AST and ALT in hepatic cells but increase of these levels in serum ${ }^{11}$.

It has been suggested that when paracetamol is taken at toxic doses, it is converted into highly toxic intermediate $\mathrm{N}$ - acetyl - pbenzoquinoneimine (NAPQI), which can rapidly deplete $90 \%$ glutathione (GSH) in cells and mitochondria which ultimately resulting mitochondrial dysfunction and hepatocellular death $^{12}$. Again, some researchers suggested that NAPQI can bind covalently to cell membrane lipids, that cause a sharp increase in lipid peroxides followed by elevation of some liver marker enzymes such as serum AST and ALT ${ }^{13}$. Cell membranes are particularly susceptible to the peroxidative reaction induced by free radicals. It has been suggested that a reduction in the activities of antioxidant enzymes is associated with the accumulation of highly reactive free radicals, leading to lipid peroxidation ${ }^{10}$.

Many studies have been carried out to find out antioxidants of natural origin. It has been postulated that mushroom has a suppressive effect on serum AST and ALT activities which may be due to presence of some unknown low molecular weight substance in mushroom ${ }^{7,8}$.

Again, by suppressing tumor necrosis factor- $\alpha$ (TNF- $\alpha$ ) and free radical scavenging activity of mushroom may be helpful in protecting the hepatocyte damage and thus reducing the serum AST and ALT levels ${ }^{14,15}$. Moreover, it has been suggested that, the extract of mushroom probably act to prevent the fall of glutathione (GSH) through some GSH dependent enzymes. Thus the structural integrity of the hepatic cell membrane is preserved and reduces the MDA concentration ${ }^{16}$.

Some active compounds present in Oyster mushroom such as $\beta$-glucan, phenol and vitamin $\mathrm{C}$ increase the activities of some antioxidant enzymes such as catalase (CAT), superoxide dismutase (SOD) and glutathione peroxidase $\left(\mathrm{GP}_{\mathrm{x}}\right)$ and thereby scavenge free radicals ${ }^{17,18}$. So this antioxidant activity of mushroom may be responsible for stabilization of hepatic cell membrane and reduction of hepatic cell necrosis ${ }^{15}$.

In the present study, hepatic damage was observed in rats treated with paracetamol as evidenced by an elevation of serum AST, ALT levels and MDA concentration in liver tissue. These changes may be due to increased production of free radicals which initiate lipid peroxidation and subsequent cell damage.Again, lower levels of serum AST and ALT were observed in mushroom pretreated and paracetamol treated rats suggested the possibility of the extract to give protection against toxin induced liver injury. These effects are most likely due to free radical scavenging activity. In addition, pretreatment with mushroom extract in 


\section{Article}

this group showed significant decreased level of MDA content in the liver tissue. Thus the maintenance of nearly normal levels of hepatic MDA provides additional evidence of hepatoprotective effect of mushroom. Moreover, changes of the liver weight of different groups of rat also support the hepatoprotective effect of Oyster mushroom.

However, the exact mechanism involved in the hepatoprotective activity of Oyster mushroom extract against paracetamol induced liver damage in rats cannot be find out from this type of study. According to the suggestions made by different investigators, free radical scavenging activities may be responsible for the hepatoprotective effect.

\section{Conclusion}

From this study it can be concluded that Oyster mushroom (Pleurotus florida) may have some hepatoprotective role. But the active component of mushroom, which is responsible for this effect actually is not known. So, further study on this aspect with larger sample size is required for definite conclusion.

\section{Acknowledgement}

Authors of this study are thankful to the authority of National Mushroom Development and Extension centre, savar, Dhaka for the cooperation regarding financial help and mushroom supply and also to Jahangirnagar University for the cooperation regarding laboratory facility they provided. The authors acknowledge the partial financial support from the research grant of DGHS of Bangladesh.

\section{Author Affiliations}

1. Afroza Khanam Sumy, Lecturer of Physiology, Enam Medical College and Hospital, Savar, Dhaka. Email;afrozakhanam58@yahoo.com.

2. Professor Nasim Jahan, professor and Head, Department of Physiology, Sir Salimullah Medical College SSMC, Mitford, Dhaka. Email; prof.dr.nasimjahan@gmail.com.

3. Nayma Sulatana, Assistant Professor, Department of Physiology, Sir Salimullah Medical College SSMC, Mitford, Dhaka. Email;nayma_sultana@yahoo.com.
Hepatoprotective Effect of Oyster Mushroom

\section{References}

1. Ganong WF. Regulation of gastrointestinal function. In: Review of Medical Physiology $23^{\text {rd }}$ ed. New York: McGraw-Hill Companies; 2005.

2. Iqbal JM. Evaluation of hepatoprotective potential of four different extracts of phyllanthus niruri on paracetamol -induced hepatotoxicity in rat [M. Phil thesis].[Dhaka]: University of Dhaka; 2001.

3. Goldin RD, Ratnayaka ID, Breach CS, Brown IN, Wichramasingfe SN. Role of macrophages in acetaminophen induced hepatotoxicity. The Journal of Pathology. 1996; 179:432-435.

4. Dahlin DC, Miwa GT, Lu AYH, Nelson SD. Nacetyl-p-benzoquinone-imine: a cytochrome P-450 mediated oxidation product of acetaminophen. Proc Natl Acad Sci USA. 1984; 81:1327-1331.

5. Michael SL, Pumford NR, Mayeux PR, Niesman MR, Hinson JA. Pretreatment of mice with macrophage inactivators decreases acetaminophen hepatotoxicity and formation of reactive oxygen and nitrogen species. Hepatology. 1999; 30: 186195.

6. Rishikesh M. Some edible oyster mushrooms of Arunachal pradesh. In: Kumar A, Bohra CP, Singh LK, editor. Environment, pollution and management. New Delhi: APH Publishing corporation; 2003; P. 349.

7. Lee EW, He P, Kawagishi H, Sugiyama K. Suppression of D-galactosamine induced liver injury by mushroom in rats. Biosci.Biotechnol.Biochem .2000; 64 (9): 2001-2004.

8. Koyama T, Chounan R, Uemura D, Yamaguchi K, Yazawa K. Hepatoprotective effect of a hot water extract from the edible thorny oyster Spondylus varius on carbon tetrachloride induced liver injury in mice. Biosci Biotechnol Biochem. 2006; 70(3): 729-731.

9. Jayakumar T, Thomas PA, Geraldine P. Protective effect of an extract of the oyster mushroom, Pleurotus ostreatus, on antioxidants of major organs of aged rats. Experimental Gerontology. 2007; 42: 183-191.

10. Rajkapoor B, Venugopal Y, Anbu J, Harikrishnan N, Gobinath M, Ravichandran V. Protective effect of Phyllanthus polyphyllus on acetaminophen induced hepatotoxicity in rats. Pak J Pharm Sci. 2008; 21(1):57-62. 
11. Yadav NP, Dixit VK. Hepatoprotective activity of leaves of Kalachoe pinnata Pers. J of Ethnopharmacology. 2003; 86: 197-202.

12. Mitchell JR, Jollow DJ, Potter WZ, Gillete JR, Brrodie BB. Paracetamol induced hepatic necrosis.Protective role of glutethione. J Pharmacol Exp Ther. 1973; 187: 211-217.

13. Kaplowitz N, Aw TY, Simon FR, Stolz A. Drug induced hepatotoxicity. Ann Intern Med. 1986; 104(6): 826.

14. Jose N, Janardhanan KK. Antioxidant and antitumour activity of Pleurotus florida. Curr Sci. 2000; 79 (7): 941-943.

15. Yang XJ, Liu J, Ye LB, Yang F, Ye L, Gao JR, Wu $\mathrm{ZH}$. In vitro and in vivo protective effects of proteoglycan isolated from mycelia of Ganoderma lucidum on carbon tetrachloride induced liver injury. World J Gastroenterol. 2006; 12(9): 1379-1385.
16. Vermeulen NPE, Bessems JGM, Straat VD. Molecular aspects of paracetamol- induced hepatotoxicity and its mechanism- based prevention. Drug Metabolism Reviews. 1992; 24(3): 367-407.

17. Bovek P, Ozdin L, Kuniak L. Effect of Oyster mushroom and on the activities of antioxidative enzymes in rats fed the cholesterol diet. The Journal of Nutritional Biochemistry. 1997; 8: 469-471.

18. Fu HY, Shieh DE, Ho CT. Antioxidant and free radical scavenging activities of edible mushrooms. J Food Lipids. 2002; 9: 35-43.

19. Refaie FM, Esmat AY, Daba AS, Taha SM. Characterization of polysaccharides from Pleurotus ostreatus mycelium: assessment of toxicity and immunomodulation in vivo. Micologia Aplicada International. 2009; 21(2): 67-75. 